\section{Properties of Composite Materials Used for Bracket Bonding}

Ana Caroline Silva Gama ${ }^{1}$, André Guaraci de Vito Moraes ${ }^{2}$, Lilyan Cardoso Yamasaki ${ }^{2}$, Alessandro Dourado Loguercio ${ }^{3}$, Ceci Nunes Carvalho ${ }^{4}$, José Bauer ${ }^{1}$
'Department of Dentistry 1, Dental School, UFMA - Federal University of Maranhão, São Luis, MA, Brazil ${ }^{2}$ Department of Biomaterials and Oral Biology, Dental School, USP University of São Paulo, São Paulo, SP, Brazil

${ }^{3}$ Department of Restorative Dentistry, Dental School, UEPG - State University of Ponta Grossa, Ponta Grossa, PR, Brazil

${ }^{4}$ Department of Endodontics, Dental School, USP - University of São Paulo, São Paulo, SP, Brazil

Correspondence: Dr. José Bauer, Rua dos Portugueses, s/n, Cidade Universitária, 65080-805 São Luís, MA, Brasil. Tel.: +55-98-33018570. e-mail: bauer@ufma.br

Key Words: orthodontic brackets, composite resins, shear strength, mechanical stress.

\section{Introduction}

Several factors might affect the bond strength of bracket to enamel, leading to debonding, such as acid etching and drying time, adhesive application mode and time and photoactivation time (1). Composite photoactivation time is particularly important because underpolymerization may result in early bracket debonding (2).

Chemically activated resin composites have been widely used in Orthodontics. These composites require mixing of two pastes, which could induce incorporation of air bubbles into the material. Other disadvantages include longer working time, slower polymerization reaction and lower mechanical properties because the incorporation of oxygen in the mass inhibits the polymerization (3). For these reasons, light-activated orthodontic composite materials have been ever more frequently used for bracket bonding to dental enamel (4). These materials are very similar to the composite resins used in restorative dentistry (5), which has led to the indication of flowable composites for bracket bonding instead of orthodontic composites (6-10). The high fluidity of flowable composites could be an advantage for bracket bonding for allowing a better adaptation in areas of anchorage and regions of demineralized enamel (11). In addition, flowable composites are usually less expensive than orthodontic composites (9) and their low modulus of elasticity could act as an "elastic layer" (12), preventing stress concentration at the tooth/bracket interface during light-activation and allowing a better dissipation of the stresses generated during occlusal movements (13).
Although not being frequently cited in studies evaluating orthodontic bracket bonding, the cavity configuration factor, or C-factor, is extremely high due to the limited number of flow-free faces (14). This may be responsible for the high stress at the adhesive interface, which may contribute directly to bracket debonding, as occurs in composite resin (or resin material) restorations in anterior and posterior teeth. To the best of our knowledge, there is only one study (15) in which the authors used simulation by finite element analysis to evaluate, among other factors, the effect of the modulus of elasticity of the cement film on the stresses generated at the bonded interface. In spite of demonstrating that the modulus of elasticity had little influence on stress generation, this factor had great impact on stress distribution within the bonded interface. Therefore, one could suggest that the modulus of elasticity and resultant polymerization stress during the polymerization procedure may be related to the bond between brackets and enamel. As far as it could be acknowledged, no study has so far addressed experimentally these properties in bonded orthodontic brackets. It is also worth mentioning that several studies have analyzed only the bond strength of flowable composites associated with bracket bonding and the results are controversial (6-10).

Thus, the aim this study was to evaluate the shear bond strength to enamel, flexural strength, flexural modulus and contraction stress of two flowable composites and one orthodontic composite. 


\section{Material and Methods}

\section{Tooth Selection and Bonding Technique}

After approval of the local Ethics Committee (Protocol \#23115003621/2010-29), 45 sound human maxillary premolars were selected and embedded in acrylic resin (Jet; Clássico Produtos Odontológicos, São Paulo, SP, Brazil) inside PVC cylinders. The buccal surface was positioned perpendicular to the bottom of the PVC cylinders in such a way that the bonding surface would be parallel to the force applied during the shear strength test. The test surface was cleaned with a superfine pumice (SS White, Rio de Janeiro, $R J$, Brazil) and water slurry in Robinson brushes (Microdont, São Paulo, SP, Brazil) mounted in a low-speed handpiece (Dabi Atlante, Ribeirão Preto, SP, Brazil) for $10 \mathrm{~s}$, followed by washing with water/air spray for $10 \mathrm{~s}$ and air drying.

Forty-five standard metal Edgewise brackets for premolars were used (Abzil, São José do Rio Preto, SP, Brazil; base area $=12.06 \mathrm{~mm}^{2}$ ). The teeth were divided into 3 groups $(n=15)$ according to the type of resin tested: Transbond XT (orthodontic composite), Filtek Z-350 flow (flowable composite; 3M/ESPE, St. Paul, MN, USA) and Opallis flow (flowable composite; FGM, Joinville, SC, Brazil). The compositions and application mode are presented in Table 1 .

Light activation was performed with a halogen lightcuring unit (Optilux 501; Kerr, Orange, CA, USA) with light intensity of $450 \mathrm{~mW} / \mathrm{cm}^{2}$ on the mesial and distal faces, with curing time of $20 \mathrm{~s}$ for each proximal face. The test specimens were kept at $37^{\circ} \mathrm{C}$ for $24 \mathrm{~h}$.

\section{Shear Bond Strength Test}

The shear bond strength test was performed in a universal test machine (model 3342; Instron Corp., Canton, MA, USA) at a crosshead speed of $0.5 \mathrm{~mm} / \mathrm{min}$. The test specimens were placed in a tensile device (Odeme Biotechnology, Joaçaba, SC, Brazil) so that a chisel would produce a force falling on the tooth/bracket interface in the occlusal/gingival direction, creating a shear stress. The load necessary to debond the bracket was recorded in $\mathrm{N}$ and the bond strength was expressed in MPa by dividing the load at failure in $\mathrm{N}$ by the surface area of the bracket in square millimeters $(\mathrm{mm})$.

\section{Adhesive Remnant Index (ARI)}

After the shear bond strength test, the fractured surface of each test specimen was evaluated under a stereoscopic loupe (Kozo Optical and Electronic Instrument Co., Ltd.) at $10 \times$ magnification to quantify the ARI scores that range from 0 to 3, where: 0 : No adhesive adhered to enamel; 1 : less than half of the adhesive adhered to enamel; 2 : Over half of the adhesive adhered to enamel; 3 : The entire adhesive is adhered to enamel, including the impression of the bracket mesh.

\section{Flexural Strength Test}

Rectangular specimens $(10 \times 2 \times 1 \mathrm{~mm})$ were fabricated by filling a stainless steel split mold (Odeme Biotechnology) onto a glass slab with one increment of composite resin using a metallic spatula. The resin was covered with another

Table 1. Materials used in the study*

\begin{tabular}{|c|c|c|}
\hline Material & Composition & Application mode \\
\hline $\begin{array}{c}\text { Condac } \\
\text { (FGM, Joinville, SC, Brazil) }\end{array}$ & $37 \%$ phosphoric acid & 1 Acid etching (30 s) \\
\hline $\begin{array}{c}\text { Primer Tranbond XT } \\
\text { (3M Unitek, Monrovia, CA, USA) }\end{array}$ & TEGDMA, Bis-GMA, and camphorquinone & 2 Washing (30 s) \\
\hline $\begin{array}{c}\text { Tranbond XT } \\
\text { (3M Unitek, Monrovia, CA, USA) }\end{array}$ & $\begin{array}{l}\text { Bis-GMA, silane, n-dimethylbenzocaine, phosphorus } \\
\text { hexafluoride, } 77 \% \text { by weight of inorganic filler (silica) }\end{array}$ & 4. Application of primer/adhesive (15-20 s) \\
\hline $\begin{array}{c}\text { Single Bond } 2 \\
\text { (3M/ESPE, St Paul, MN, USA) }\end{array}$ & $\begin{array}{l}\text { Ethanol, Bis-GMA, filler treated with silane, } \\
\text { 2-hydroxyl methacrylate (2-hydroxirtilmethacrilate), } \\
\text { glycerol 1, 3-dimethacrylate, copolymer of } \\
\text { itaconic acid and diurethane dimethacrylate. }\end{array}$ & $\begin{array}{l}\text { 5. Air drying (15 s) at a distance of } 20 \mathrm{~cm} \\
\text { 6. Light curing (10 s) }\end{array}$ \\
\hline $\begin{array}{l}\text { Opallis Flow A2 } \\
\text { (FGM, Joinville, SC, Brazil) }\end{array}$ & $\begin{array}{l}\text { Bis-GMA, TEGDMA, Bis-EMA, 72\% by weight of inorganic } \\
\text { filler (barium-aluminum silicate and silicon dioxide) }\end{array}$ & 7. Application of resin on bracket base \\
\hline $\begin{array}{c}\text { Filtek Z-350 Flow A2 } \\
\text { (3M/ESPE, St Paul, MN, USA) }\end{array}$ & $\begin{array}{l}\text { Bis-GMA, TEGDMA, Bis-EMA, } 65 \% \text { by weight } \\
\text { of inorganic filler (silica and zirconium) }\end{array}$ & $\begin{array}{l}\text { 8. Light activation (40 s) } 450 \mathrm{~mW} / \mathrm{cm}^{2} \\
\text { Energy dose: } 18 \mathrm{~J} / \mathrm{cm}^{2}\end{array}$ \\
\hline
\end{tabular}


glass slab and gently pressed against the mold to extrude excess material. The entire cavity was filled with the same materials used for bonding brackets. Ten specimens were made with each material, for a total of 30 specimens $(n=10)$. Light activation was performed for $40 \mathrm{~s}$ using a halogen light-curing unit (Optilux 501) with an energy density of $18 \mathrm{~J} / \mathrm{cm}^{2}$. The specimens were stored in water for $24 \mathrm{~h}$ at $37^{\circ} \mathrm{C}$ immediately after the test.

Three-point flexural bending was performed in the same universal testing machine (model 3342 ; Instron Corp.) at a crosshead speed of $0.5 \mathrm{~mm} / \mathrm{min}$. The flexural strength was calculated using the following equation:

$$
\sigma=\frac{3 \mathrm{Fl}}{2 \mathrm{bh}^{2}},
$$

where $\sigma$ is the flexural strength (MPa), $F$ is the load necessary for fracture, $I$ is the distance between the supports $(6 \mathrm{~mm})$ and $\mathrm{b}$ and $\mathrm{h}$ are the test specimen's width and height $(\mathrm{mm})$, respectively .

The data used to obtain the modulus of elasticity were taken from the flexural strength test; that is, when the test was performed, a computer coupled to the test machine used the load values, for each test specimen, corresponding to the displacement of the active tip. Each load value and corresponding displacement value was inserted in the following equation to obtain the FM value, which is the modulus of elasticity from the flexion test:

$$
\mathrm{FM}=\frac{\mathrm{f} 1 . \mathrm{I}^{\underline{3}}}{4 \mathrm{~b} \cdot \mathrm{h}^{3} \cdot \mathrm{d}}
$$

where, $\mathrm{f} 1$ is the load recorded at time (1), I is the distance between the supports, $b$ and $h$ are the height and width of the test specimen $(\mathrm{mm})$, respectively, and $d$ is the deflexion $(\mathrm{mm})$ corresponding to $\mathrm{f1}$.

\section{Polymerization Contraction Stress Test}

The test was performed with poly (methyl methacrylate) - PMMA cylinders, $5 \mathrm{~mm}$ in diameter and $13 \mathrm{~mm}$ long, used as substrates for the composites. The ends of the cylinders were polished with a sequence of 600 - to 4000 -grit silicon carbide papers followed by 3 or $1 / 4 \mu \mathrm{m}$ diamond paste in soft felt polishing pad (Buehler-MetaDi; Buehler Ltd. Lake Bluff, IL, USA). A universal testing machine (Instron 5565) was used, and the shorter cylinders were fixed to the bottom clasp on the polymerization stress device, and the longer cylinders to the top clasp, with a distance of $1 \mathrm{~mm}$ (C factor $=2.5$; volume $=16 \mathrm{~mm}^{3}$ ) between them. After insertion of the composite, the transducer - extensometer (model 2630-101, Instron Corp.) was coupled to the cylinders to maintain the distance between them during the test.

Light activation of the composite resin was performed for $40 \mathrm{~s}$ using a halogen light-curing unit (Optilux 501) with an energy density of $18 \mathrm{~J} / \mathrm{cm}^{2}$. The test was monitored for $10 \mathrm{~min}$ from the beginning of light activation. Five specimens were tested for each of the flowable composites and the orthodontic composite $(n=5)$.

Data from all tests were subjected to statistical analysis by one-way ANOVA and Tukey's test ( $\alpha=0.05)$.
Table 2. Means and standard deviations of shear bond strength (MPa), flexural strength (MPa), flexural modulus ( $\mathrm{GPa}$ ) and polymerization contraction stress (MPa) of the tested materials

\begin{tabular}{lcccc}
\hline Composites & $\begin{array}{c}\text { Bond } \\
\text { strength }\end{array}$ & $\begin{array}{c}\text { Flexural } \\
\text { strength }\end{array}$ & $\begin{array}{c}\text { Flexural } \\
\text { modulus }\end{array}$ & $\begin{array}{c}\text { Contraction } \\
\text { stress }\end{array}$ \\
\hline Tranbond XT & $25.1 \pm 4.4^{\mathrm{a}}$ & $152.7 \pm 31.4^{\mathrm{A}}$ & $4.7 \pm 2.9 \mathrm{~b}$ & $2.2 \pm 0.1 \mathrm{C}$ \\
Opallis Flow A2 & $15.6 \pm 5.8^{\mathrm{b}}$ & $140.9 \pm 32.7^{\mathrm{A}}$ & $2.5 \pm 0.7 \mathrm{a}$ & $4.9 \pm 0.4 \mathrm{~A}$ \\
Filtek Z-350 Flow A2 & $16.9 \pm 8.0^{\mathrm{b}}$ & $155.8 \pm 30.1^{\mathrm{A}}$ & $2.2 \pm 0.3 \mathrm{a}$ & $4.3 \pm 0.3 \mathrm{~B}$ \\
\hline
\end{tabular}

Different lowercase or uppercase letters, either superscript or not, indicate statistically significant difference among the groups (Tukey's test, $\mathrm{p}<0.05$ ).

Table 3. Adhesive Remnant Index (ARI) recorded in the groups

\begin{tabular}{lccccc}
\hline \multirow{2}{*}{ Composite } & \multicolumn{3}{c}{ Adhesive remnant index } & Fractured \\
\cline { 2 - 5 } & 0 & 1 & 2 & 3 & enamel \\
\hline Tranbond XT & 0 & 13 & 1 & 0 & 1 \\
Opallis Flow A2 & 0 & 11 & 4 & 0 & 0 \\
Filtek Z-350 Flow A2 & 0 & 13 & 1 & 0 & 1 \\
\hline
\end{tabular}

0 : No adhesive adhered to enamel; 1 : less than half of the adhesive adhered to enamel; 2: Over half of the adhesive adhered to enamel; 3 : The entire adhesive is adhered to enamel, including the impression of the bracket mesh.

\section{Results}

The means and standard deviations of shear bond strength (MPa), flexural strength (MPa), flexural modulus (GPa) and polymerization contraction stress (MPa) of the materials are shown in Table 2.

There was no statistically significant difference among the composites for flexural strength ( $p>0.05$ ). For shear bond strength, Transbond XT presented the highest values $(p<0.05)$ and the other materials were similar to each other ( $p>0.05$ ). As regards the ARI, score 1 was the most frequent in all groups, followed by score 2 (Table 3).

For the flexural modulus, Filtek Z-350 flow and Opallis flow presented the lowest values $(p<0.05)$. For polymerization contraction stress, Transbond XT presented the lowest value, Filtek Z-350 flow the highest value $(p<0.05)$ and Opallis flow presented an intermediate stress value, differing significantly from the other materials $(p<0.05)$. 


\section{Discussion}

The bond strength values found in this study for flowable composites were significantly lower compared with those found for Transbond XT. Some studies have also found lower bond strength values for flowable composites when compared with an orthodontic composite $(7,10,16)$. However, these results are controversial $(6,8,9)$. Thus, continuous evaluations of the mechanical behavior of composites is an attempt to understand the reasons for the different results of shear bond strength tests found in the literature (17).

Transbond XT presented higher modulus of elasticity than Filtek Z-350 flow and Opallis, which seems to be a reasonable result, as the orthodontic composite has greater filler content $(77 \%)$ than the flowable composites, Filtek Z-350 flow (65\%) and Opallis (72\%). The filler is generally responsible for the increase of the mechanical properties of the material (18). However, the increase in the quantity of filler would not have any direct relationship with the increase in bond strength of the materials, since the involved materials had a minimum intrinsic strength to bear the forces to which they were submitted during the test.

The $\mathrm{C}$-factor is extremely high at the adhesive interface formed between the bracket and the dental enamel. The role of $\mathrm{C}$-factor in the development of polymerization stress in composite materials was first demonstrated by Feilzer et al. (19), who described that when two rigid surfaces are united, such as the bond between dental enamel and the metal bracket, the only region responsible for release of the stresses generated by polymerization contraction, elastic deformation of the material and flow is the free part in the thin film of composite material between the enamel and bracket (20).

Therefore, the $\mathrm{C}$-factor is given by the ratio between the bonded surfaces and the free surfaces, and the smaller the non-bonded surface area, the smaller the possibility for the cement material to flow, and thus the greater the polymerization stress generated at the adhesive interface (14). Considering the size of the bracket area and the approximate thickness of the cement film (more or less $0.3 \mathrm{~mm}$ ) (14), the C-factor of a bracket bond is around 6 . This means that the stress generated at the bracket-enamel interface is extremely high. Therefore, the use of materials with a lower flexural modulus may generate lower stresses and diminish the impact of polymerization on the bonded interface.

Based on the Feilzer's et al. theory (19), it was to be expected that Transbond XT, which is the material with the highest flexural modulus would also cause the highest polymerization stress values, as shown by Condon and Ferracane (21). However, the results from the polymerization contraction stress test of the composites showed that the flowable composites generated a statistically higher stress when compared with Transbond XT. Gonçalves et al (22) showed that the composite matrix had a stronger influence on polymerization stress, conversion and reaction rate, when different BisGMA:TEGDMA ratios were compared, whereas filler fraction showed a stronger influence on shrinkage and modulus. Thus, materials with a high percentage of diluent monomers of low molecular weight, such as TEGDMA, present high volumetric contraction, and consequently, high contraction stress values, due to increase of the conversion rate (23). Perhaps the presence of diluent monomers (TEGDMA and Bis-EMA) and low filler content in Filtek Z-350 flow and Opallis, may have contributed to a statistically higher contraction stress when compared with Transbond XT.

Higher ARI values are favorable for avoiding damage to the enamel, as the residue may safely be removed with suitable rotary instruments. In the present study there was higher prevalence of ARI $1(82 \%)$ and $2(13 \%)$ values in all groups, thus detecting a failure in the bonding to enamel, or greater retention of the adhesive material to the bracket, as shown in previous studies $(1,24)$.

Considering the limitations of this study, it may be concluded that the light-activated orthodontic composite showed the highest shear bond strength and flexural modulus, and the lowest contraction stress values in a comparison with flowable composites.

\section{Resumo}

0 objetivo desse estudo foi avaliar a resistência ao cisalhamento no esmalte, resistência flexural, módulo flexural, tensão de contração de polimerização de duas resinas flowe uma resina ortodôntica. Os bráquetes ortodônticos foram colados em 45 pré-molares humanos e divididos: Transbond XT, Filtek Z-350 flow, Opallis flow e testado para resistência ao cisalhamento $(n=15)$. Para a resistência e módulo flexural espécimes foram confeccionados e testados sob flexão. Para o teste de tensão de contração de polimerização, espécimes cilindricos foram confeccionadose monitorados com um extensômetro (Instron). Os dados foram submetidos aos testes ANOVA a um critério e Tukey $(\alpha=0,05)$ para contraste de média. $(n=15)$. A resistência de união das resinas flow foram significantemente menos que o da resina ortodôntica $(p>0,05)$. A resistência flexural não demonstrou diferença significante entre os grupos testados $(p>0,05)$. 0 módulo flexural da resina ortodôntica foi significantemente maior que o grupo das resinas flow $(p<0,05)$. A tensão de contração de polimerização da resina ortodôntica foi significantemente menor $(p<0,05)$. A resina ortodôntica obteve os maiores valores de resistência de união ao cisalhamento, resistência flexural e a menor tensão de contração de polimerização quando comparada as resinas flow testadas.

\section{Acknowledgements}

The study was supported by grant from the Foundation for the Support of Scientific and Technological Research of Maranhão (FAPEMA - 01164/09 and 00705/11).

\section{References}

1. Parrish BC, Katona TR, Isikbay SC, Stewart KT, Kula KS. The effects of 
application time of a self-etching primer and debonding methods on bracket bond strength. Angle Orthod 2012;82:131-136.

2. Dall'Igna CM, Marchioro EM, Spohr AM, Mota EG. Effect of curing time on the bond strength of a bracket-bonding system cured with a light-emitting diode or plasma arc light. Eur J Orthod 2011;33:55-59.

3. Caughman WF, Ruggerberg FA. Shedding new light on composite polymerization. Oper Dent 2002;27:636-638.

4. Hegarty DJ, Macfarlane TV. In vivo bracket retention comparison of a resin modified glass ionomer cement and a resin-based bracket adhesive system after a year. Am J Orthod Dentofacial Orthop 2002;121:496-501.

5. Neme AL, Maxson BB, Pink FE, Aksu MN. Microleakage of class II packable resin composites lined with flowables: An in vitro study. Oper Dent 2002;27:600-605.

6. Tabrizi S, Salemis E, Usumez S. Flowable composites for bonding orthodontic retainers. Angle Orthod 2010;80:195-200.

7. Ryou DB, Park HS, Kim KH, Kwon TY. Use of flowable composites for orthodontic bracket bonding. Angle Orthod 2008;78:1105-1109.

8. D'Attilio M, Traini T, Di lorio D, Varvara G, Festa F, Tecco S. Shear bond strength, bond failure, and scanning electron microscopy analysis of a new flowable composite for orthodontic use. Angle Orthod 2005;75:410-415.

9. Pick B, Rosa V, Azeredo TR, Cruz Filho EA, Miranda WG Jr. Are flowable resin-based composites a reliable material for metal orthodontic bracket bonding? J Contemp Dent Pract 2010;11:17-24.

10. Uysal T, Sari Z, Demir A. Are the flowable composites suitable for orthodontic bracket bonding? Angle Orthod 2004;74:697-702.

11. Frankenberger R, Lopes M, Perdigão J, Ambrose WW, Rosa BT. The use of flowable composites as filled adhesives. Dent Mater 2002;18:227-238.

12. Ferracane JL. Developing a more complete understanding of stresses produced in dental composites during polymerization. Dent Mater 2005;21:36-42.

13. De Munck J, Van Landuyt $K L$, Coutinho $E$, Poitevin A, Peumans $M$, Lambrechts $P$, et al.. Fatigue resistance of dentin/composite interfaces with an additional intermediate elastic layer. Eur J Oral Sci
2005; 113:77-82

14. Davidson $\mathrm{CL}$, Feilzer AJ. Polymerization shrinkage and polymerization shrinkage stress in polymer-based restoratives. J Dent 1997;25:435440.

15. Knox J, Kralj B, Hübsch PF, Middleton J, Jones ML. An evaluation of the influence of orthodontic adhesive on the stresses generated in a bonded bracket finite element model. Am J Orthod Dentofacial Orthop 2001;119:43-53.

16. Park SB, Son WS, Ko CC, Garcia-Godoy F, Park MG, Kim H, et al.. Influence of flowable resins on the shear bond strength of orthodontic brackets. Dent Mater J 2009; 28:730-734.

17. Vicente A, Bravo LA. Evaluation of different flowable materials for bonding brackets. Am J Dent 2009;22:111-114.

18. Boaro LC, Gonçalves F, Guimarães TC, Ferracane JL, Versluis A, Braga RR. Polymerization stress, shrinkage and elastic modulus of current low-shrinkage restorative composites. Dent Mater 2010;26:1144-1150.

19. Feilzer AJ, De Gee AJ, Davidson CL. Setting stress in composite resin in relation to configuration of the restoration. J Dent Res 1987;66:16361639.

20. Carvalho RM, Yoshiyama M, Pashley EL, Pashley DH. A review of polymerization contraction: the influence of stress development versus stress relief. Oper Dent 1996;21:17-24.

21. Condon JR, Ferracane JL. Assessing the effect of composite formulation on polymerization stress. J Am Dent Assoc 2000;131:497-503.

22. Gonçalves $\mathrm{F}$, Azevedo $\mathrm{CL}$, Ferracane JL, Braga RR. BisGMA/TEGDMA ratio and filler content effects on shrinkage stress. Dent Mater 2011;27:520526.

23. Braga RR, Ballaster RY, Ferracane JL. Factors involved in the development of polymerization shrinkage stress in resin-composites: a systematic review. Dent Mater 2005; 21:962-970.

24. Leódido $\mathrm{G}$ da $\mathrm{R}$, Fernandes $\mathrm{HO}$, Tonetto $M R$, Presoto $C D$, Bandéca MC, Firoozmand LM. Effect of fluoride solutions on the shear bond strength of orthodontic brackets. Braz Dent J 2012;23:698-702.

Received February 14, 2013 Accepted May 7, 2013 